\title{
Morphology and Photoelectrochemical Characterization of MEH-PPV/PCBM Composite Film Doped with $\mathrm{TiO}_{2}$ Nanoparticles
}

Farid Habelhames ${ }^{1) \dagger}$, Zerguine Wided $^{1)}$, Leila Lamiri ${ }^{1)}$, Belkacem Nessark ${ }^{1)}$ and Hassina Derbal-Habak ${ }^{2}$

1) Laboratoire d'électrochimie et matériaux (LEM), Faculté de Technologie. Département de génie des Université Ferhat Abbas Sétif 1, 19000, Algérie

2) ECOLE POLYTECHNIQUE, LPICM Laboratory, ORGATECH Team Route de Saclay Paris, France

[Manuscript received 20 December 2012, in revised form 28 March 2013]

(c) The Chinese Society for Metals and Springer-Verlag Berlin Heidelberg

Poly[2-methoxy-5-(20-ethylhexyloxy)-p-phenylenevinylene] (MEH-PPV), [6,6]-phenyl-C61-butyric acid methyl ester (PCBM) and titanium dioxide $\left(\mathrm{TiO}_{2}\right)$ nanoparticles ( $\mathrm{n}$-type) were dissolved, mixed and deposited by physical methods (spin-coating) on indium tin-oxide (ITO) substrate. The incorporation of the titanium dioxide nanoparticles changed the morphology and increased the roughness of polymers film (MEH-PPV/PCBM), and the photocurrent density of the composite (MEH-PPV/PCBM $+n-\mathrm{TiO}_{2}$ ) was higher than that of single MEH$\mathrm{PPV} / \mathrm{PCBM}$ film. The study showed that the presence of $\mathrm{n}-\mathrm{TiO}_{2}$ particles in the polymeric film improves the photoelectrochemical properties of MEH-PPV/PCBM composite.

KEY WORDS: Photocurrent density; Electrochemical property; Hybrid coating; Conducting polymer; Titanium dioxide; Organic nanostructures

\section{Introduction}

The performance of the photovoltaic devices with a light absorber consisting of a single-type conjugated polymer is poor, due to a low photo-generation yield of charge carriers, strong radiative recombinations and low mobility of charge carriers ${ }^{[1]}$. Conjugated polymer photovoltaic devices have many positive properties that may provide the means to overcome the current hurdles toward low-cost photovoltaics.

However, polymer-based organic photovoltaic are presently limited in their power efficiency due to a number of device and material parameters that have yet to be optimized. The first such limitation is that the band gap of the conjugated polymers needs to be decreased in order to absorb a larger portion of the solar spectrum and increase the photocurrent. The

\footnotetext{
† Corresponding author. Ph.D.; Tel: +213 36925121; Fax: +213 36925133; E-mail address: habelhamesfarid@yahoo.fr (Farid Habelhames)
}

DOI: $10.1007 / \mathrm{S} 40195-012-0269-\mathrm{z}$ photovoltage could be increased by the proper optimization of the band offsets, where the lowest unoccupied molecular orbital of the donor and the valence band of the acceptor are close in energy, but still allow for efficient electron transfer. If the band alignment between donor and acceptor materials was more appropriately engineered through the proper selection and design of active materials, this lost energy could be utilized resulting in improved device performance $^{[2-5]}$.

Conducting polymers have been examined so far for stability in solar cells, mainly the poly[2-methoxy5-(20-ethyl-hexyloxy)-1,4-phenylenevinylene] (MEH$\mathrm{PPV})^{[6]}, \mathrm{P} 3 \mathrm{HT}^{[7]}$ and $\mathrm{P} 3 \mathrm{CT}{ }^{[8]}$.

MEH-PPV is a photoactive polymer known to form excitons upon exposure to light ${ }^{[9]}$. Despite low electron mobility, MEH-PPV has been utilized in solar cells research due to high absorbance in the visible region $^{[10]}$. Because MEH-PPV possess high hole mobility, it is often paired with an electron carrier to generate photovoltaic devices ${ }^{[11]}$.

At the same time, the concept of the photovoltaic (PV) device structure has also evolved from single 

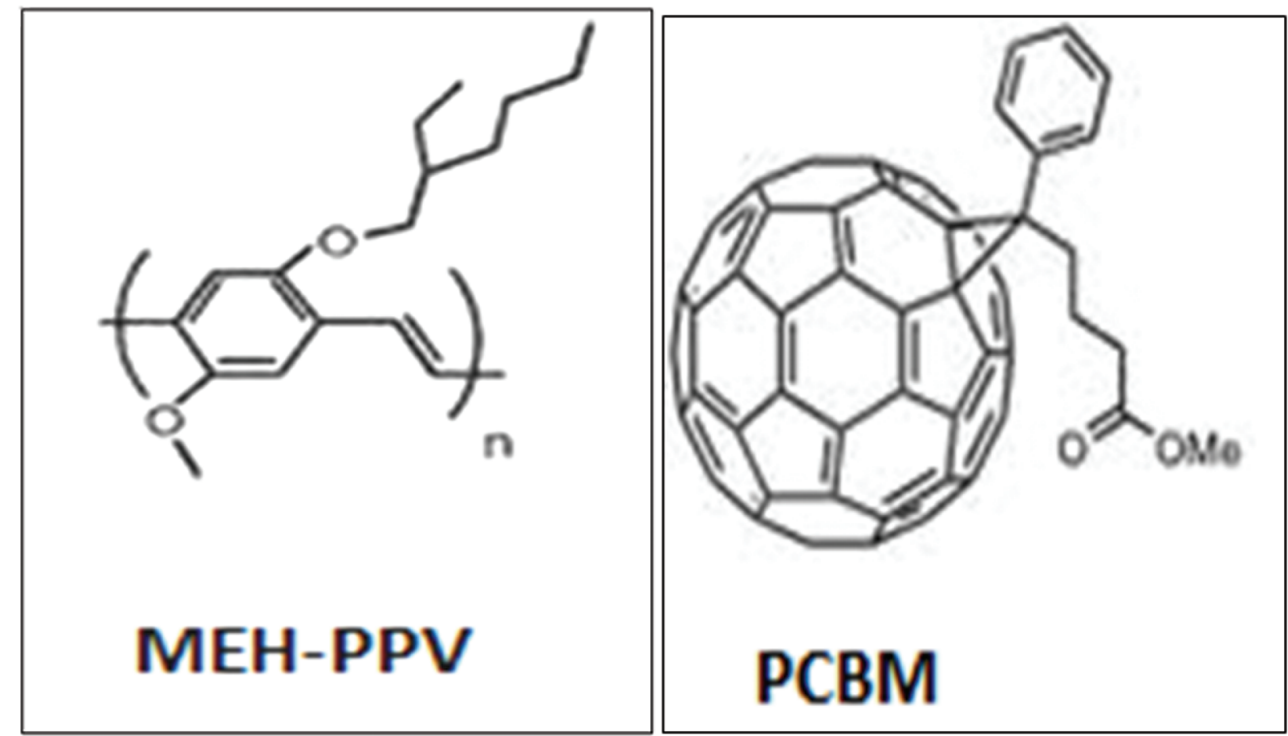

Fig. 1 Sketch of the molecular structures of poly[2-methoxy-5-(2-ethylhexyl-oxy)-p-phenylenevinylene] (MEHPPV) and the fullerene 1-(3-methoxycarbonylpropyl)-1-phenyl-[6.6]C 61 (PCBM)

layer ${ }^{[12]}$, double layer ${ }^{[13]}$ to bulk heterojunction $(\mathrm{BHJ})^{[14]}$, which is now the most successful and widely adopted organic PV device structure. The active layer of bulk heterojunction is typically composed of a conjugated polymer (electron donating molecule) and fullerene derivative such as $\mathrm{C}_{60}$ or PCBM (electron accepting molecule $)^{[15-17]}$.

Recently, it has been shown that ultra-fast photoinduced charge transfer can also occur between a conjugated polymer and a metal oxide semiconductor such as $\mathrm{SnO}_{2}, \mathrm{TiO}_{2}, \mathrm{ZnO}, \mathrm{Nb}_{2} \mathrm{O}_{5}$, etc. ${ }^{[18,19]}$. This has led to the fabrication of photovoltaic devices based on composites of oxide semiconductor nanoparticles embedded in a conjugated polymer matrix ${ }^{[20]}$. Polymeric materials could be deposited by the solutionbased technique or electrochemical polymerization onto printable, flexible and large-scale film promising for various applications and commercialization of solar cells ${ }^{[21]}$.

In this work, we present the results of the enhancement of photoelectrochemical properties of bulk conjugated polymers, MEH-PPV and PCBM (Fig. 1) by the addition of $\mathrm{n}-\mathrm{TiO}_{2}$ nanoparticles (acceptor), which improve the performance of this photovoltaic device.

\section{Experimental}

Soluble MEH-PPV (Aldrich), PCBM and n- $\mathrm{TiO}_{2}$ nanoparticles (40-80 nm) were dissolved in chlorobenzene and stirred during $12 \mathrm{~h}$ (Fig. 2). The indium tin-oxide (ITO, from Merck with a sheet resistance $\sim 10 \Omega / \mathrm{K})$ substrates were successively cleaned for $20 \mathrm{~min}$ in water and acetone in an ultrasonic bath and finally dried at $120{ }^{\circ} \mathrm{C}$. Once dissolved, MEH$\mathrm{PPV} / \mathrm{PCBM}+\mathrm{n}-\mathrm{TiO}_{2}$ solution was dropped on ITO substrate (step 1) and spin-coated by using spinner speed of about $900 \mathrm{r} / \mathrm{min}$ for $40 \mathrm{~s}$ (step 2). Following deposition, films are dried at $80{ }^{\circ} \mathrm{C}$ for $15 \mathrm{~min}$ to evaporate the solvent (step 3). The thickness of the film, measured via an Ambios Technology XP-2 surface profiler, varied from 100 to $120 \mathrm{~nm}$.

Morphology of the coated active layer $\mathrm{MEH}-$ $\mathrm{PPV} / \mathrm{PCBM}+\mathrm{n}-\mathrm{TiO}_{2}$ composite was examined by means of atomic force microscopy (AFM), using an electron microscope ULTRA 55 (Zeiss, France).

The electrochemical analysis including cyclic voltammetry of the single-layer MEH-PPV/PCBM or $\mathrm{MEH}-\mathrm{PPV} / \mathrm{PCBM}+\mathrm{n}-\mathrm{TiO}_{2}$ composite film deposited on ITO (working electrode) by spin-coating were carried out in a one-compartment cell connected to a potentiostat/galvanostat (PGZ-301 Voltalab) coupled with a computer equipped with software (voltamaster 4) which makes it possible to select the electrochemical technique and to fix the parameters desired. The reference electrode is a saturated calomel electrode with $\mathrm{KCl}$ (SCE), and the auxiliary electrode is a platinum plate. The supporting electrolyte was 0.1 $\mathrm{mol} / \mathrm{L}$ lithium perchlorate $\left(\mathrm{LiClO}_{4}\right.$, Fluka) dissolved in acetonitrile solvent $\left(\mathrm{CH}_{3} \mathrm{CN}\right.$, Aldrich).

The cyclic voltammogram $(\mathrm{CV})$ was recorded at scan rate of $v=50 \mathrm{mV} / \mathrm{s}$ in the potential range of -1.5 to $1.8 \mathrm{~V}$ (vs. SCE). The identical cell used in the photocurrent measurements and was recorded with a $500 \mathrm{~W}$ halogen lamp as polychromatic light source, and the illumination intensity is $100 \mathrm{~mW} / \mathrm{cm}^{2}$. All measurements were taken at the atmosphere and room temperature.

\section{Results and Discussion}

\subsection{Atomic force microscopy}

The surface topography of MEH-PPV/PCBM+ $\mathrm{n}-\mathrm{TiO}_{2}$ composites film ( 100 nm of thickness) 


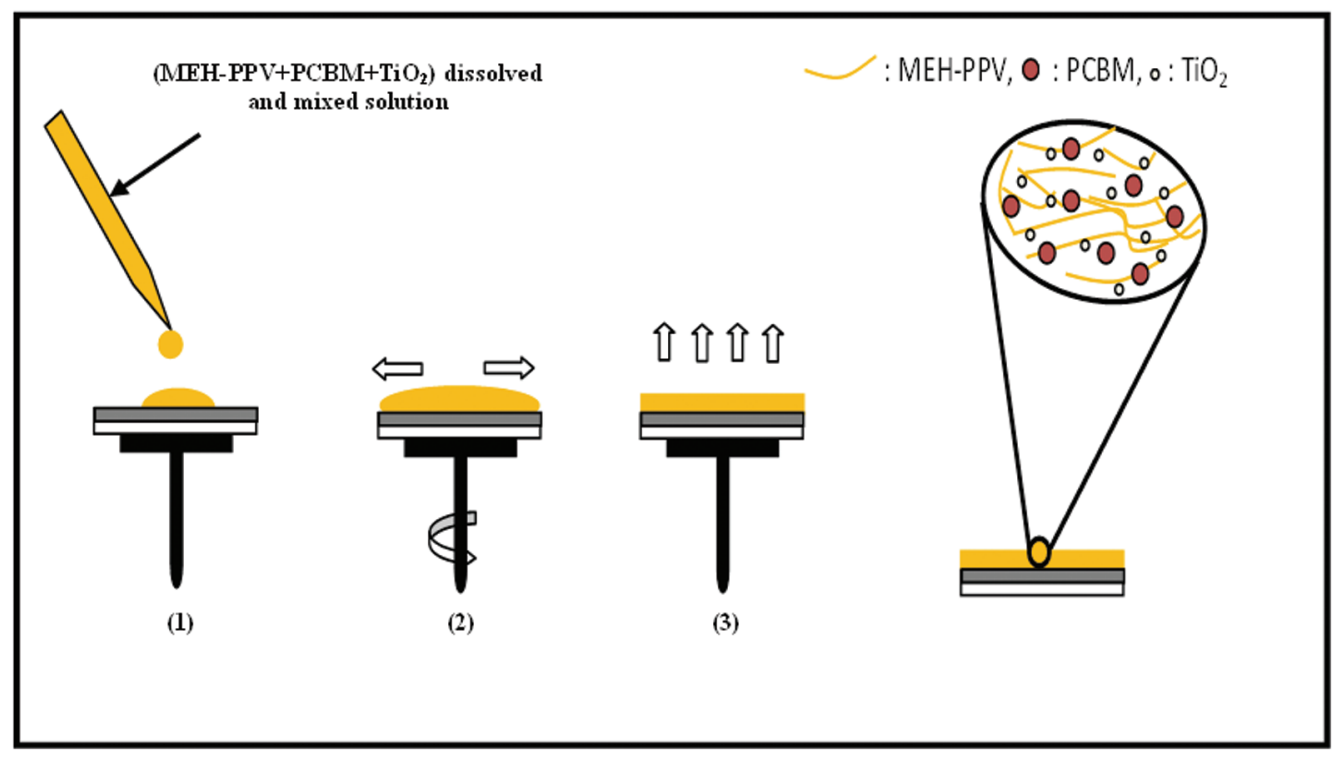

Fig. 2 Schema of experimental preparation methods
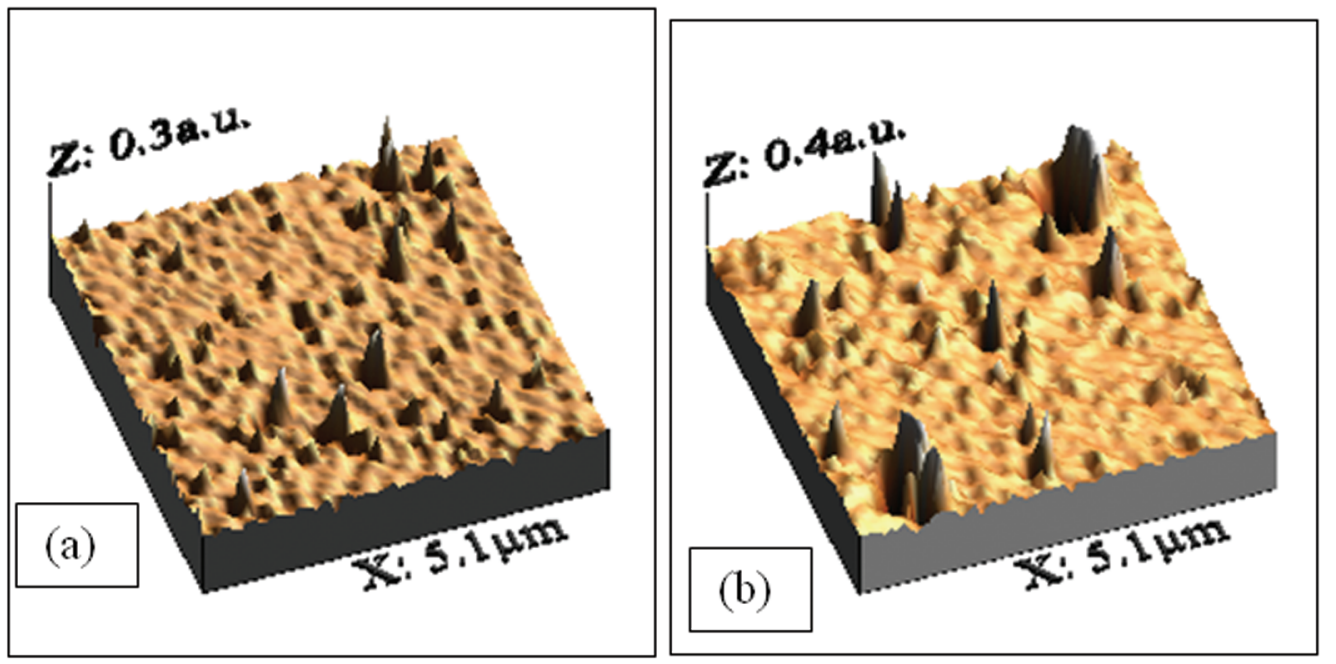

Fig. 3 AFM images of MEH-PPV/PCBM (a) and MEH-PPV/PCBM+n- $\mathrm{TiO}_{2}$ (b) composite films

revealed contact-mode atomic force microscopy, as shown in Fig. 3. Generally, AFM image can give information about the height differences and also about the constituency of the composite thin film at the surface because the hard nanoparticle can easily be distinguished from the soft polymer. And it's shown the addition of titanium dioxide $\left(\mathrm{n}-\mathrm{TiO}_{2}\right)$ nanoparticles increases the roughness (root mean square) of polymer film ${ }^{[22]}$, from $7.63 \mathrm{~nm}$ of (MEH-PPV/PCBM) to $19.76 \mathrm{~nm}$ of $\left(\mathrm{MEH}-\mathrm{PPV} / \mathrm{PCBM}+\mathrm{n}-\mathrm{TiO}_{2}\right)$. A feature of a dispersion of $\mathrm{n}-\mathrm{TiO}_{2}$ nanoparticle structure is found and inevitably leads to provide more organic/inorganic interfaces forming their own networks in the active layer.

The results indicate that the interpenetrating network and the small feature size the $\mathrm{MEH}-$ $\mathrm{PPV} / \mathrm{PCBM}+\mathrm{n}-\mathrm{TiO}_{2}$ film will facilitate more effi- cient exciton dissociation, provide more conducting channels for charge transfer and then lead to enhance device performance.

\subsection{Cyclic voltammetry}

The cyclic voltammorgams (CVs) of composite materials (MEH-PPV/PCBM), obtained for different concentration of $\mathrm{n}-\mathrm{TiO}_{2}$ nonoparticle deposited an ITO electrode, in $\mathrm{CH}_{3} \mathrm{CN} / \mathrm{LiClO}_{4}(0.1 \mathrm{~mol} / \mathrm{L})$ electrolyte solution (Fig. 4) shows for all $\mathrm{CVs}$ tow peak of oxidation at 0.5 and $0.8 \mathrm{~V}$ (vs. SCE) correspondents to first and second oxidation of MEH-PPV respectively, another peak at $1.22 \mathrm{~V}$ (vs. SCE) correspondent to the oxidation of PCBM.

In the return scan, it was observed that three peaks at $0.2,0.75$ and $-0.9 \mathrm{~V}$ (vs. SCE) which corre- 


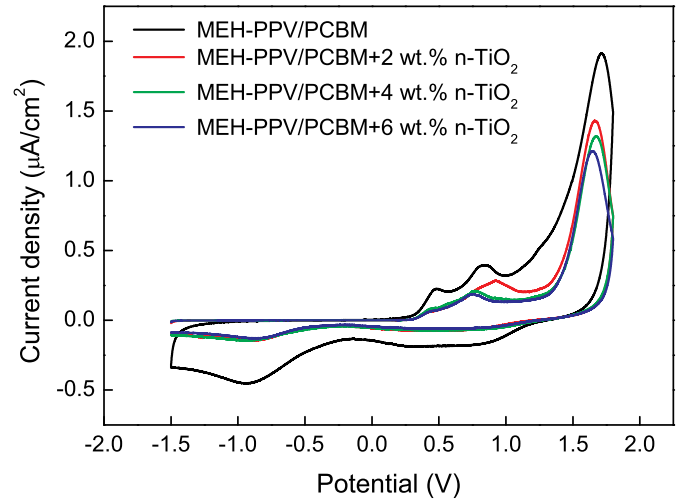

Fig. 4 Cyclic voltammograms of $\mathrm{MEH}-\mathrm{PPV} / \mathrm{PCBM}$ film and MEH-PPV $/ \mathrm{PCBM}+\mathrm{TiO}_{2}$ composites in $\mathrm{CH}_{3} \mathrm{CN} / \mathrm{LiClO}_{4}$ solution

spondent to the first and second reduction of $\mathrm{MEH}-$ PPV and the reduction of PCBM respectively. Currents densities of oxidation and reduction peaks increase with the content of $\mathrm{n}-\mathrm{TiO}_{2}$. The absence of another peak in the $\mathrm{CVs}$ of the composite materials $\left(\mathrm{MEH}-\mathrm{PPV} / \mathrm{PCBM}+\mathrm{n}-\mathrm{TiO}_{2}\right)$ can be explained by the fact that the inorganic semiconductor $\left(\mathrm{TiO}_{2}\right)$ is electrochemical but not electro activated because of its insolubility in the medium in the experimental conditions.

The observed electrochemical stability of the composite material (MEH-PPV/PCBM+n- $\mathrm{TiO}_{2}$ ) is in good agreement with the cyclic voltammograms of other organic/inorganic composites given in the literature $^{[23-26]}$.

\subsection{Photo-electrochemistry}

$\mathrm{MEH}-\mathrm{PPV} / \mathrm{PCBM}$ and $\mathrm{MEH}-\mathrm{PPV} / \mathrm{PCBM}$ $+\mathrm{n}-\mathrm{TiO}_{2}$ composite films deposited ITO sub- strate (Fig. 5(a)) used as working electrode in photoelectrochemical cell (Fig. 5(b)) containing acetonitrile $/ \mathrm{LiClO}_{4}(0.1 \mathrm{~mol} / \mathrm{L})$ electrolyte solution.

Typical photocurrent-time curves are given in Fig. 6 upon switching the light on and off, with an applied potential of $-0.6 \mathrm{~V}$ (vs. SCE). It can be seen that the polymers and the composite film featured a pronounced cathodic photocurrent and it has been shown that polymers modified with n$\mathrm{TiO}_{2}$ (6 wt.\%) semiconductor particles could feature higher photocurrents as compared to the pure polymers (MEH-PPV/PCBM) by a factor of $5(0.5 \mu \mathrm{A}$ to $2.5 \mu \mathrm{A})$.

Fig. 7 shows the photocurrent density as function of applied potential ( -1 to $1 \mathrm{~V}$ (vs. SCE)) of MEH-PPV/PCBM + 6 wt. $\%$ n-TiO 2$) /$ ITO electrode obtained at light intensity of $100 \mathrm{~mW} / \mathrm{cm}^{2}$. It was observed that the photocurrent of the composite with inorganic semiconductor nanoparticles $\left(\mathrm{TiO}_{2}\right)$ at all range of potential was negative and higher than of non-modified polymers ${ }^{[25,27]}$. This response indicates that recombination processes occur in the film, probably due to the presence of charge carriers in the polymer bulk, mainly due to structural disorder. The presence of the space-charge region suggests that these polymers may produce photocurrent when illuminated. Furthermore, it has been shown that polymers modified with $\mathrm{n}-\mathrm{TiO}_{2}$ semiconductor particles could feature higher photocurrents as compared to the pure polymers, MEH-PPV/PCBM.

As expected, the addition of the inorganic semiconductor nanoparticles into the polymers film $(\mathrm{MEH}-\mathrm{PPV}+\mathrm{PCBM})$ increases the photocurrent, assuring more efficient exciton dissociation, and provide more conducting channels for charge transfer and then lead to enhance the polymer photovoltaic proprieties $^{[25-28]}$.

(b)

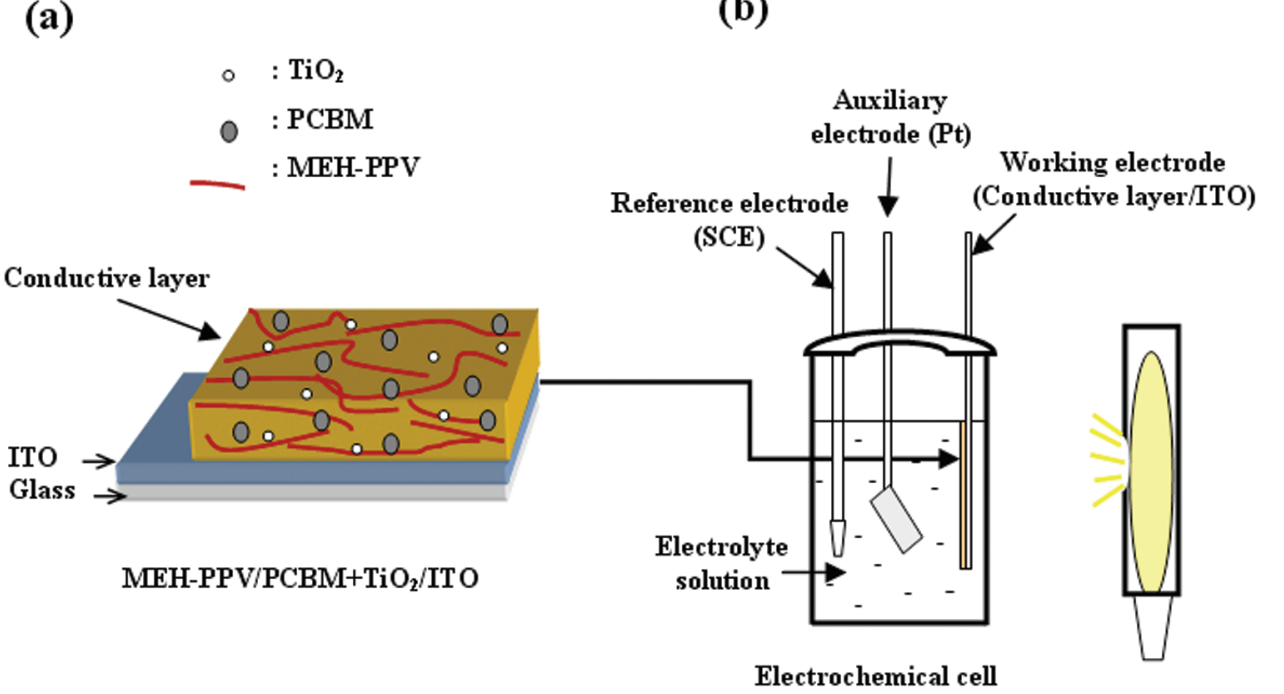

Polychromatic lamp

Fig. 5 (MEH-PPV/PCBM+n- $\mathrm{TiO}_{2}$ ) ITO photovoltaic structure (a) and schematic of photoelectichemical experimental technique (b) 


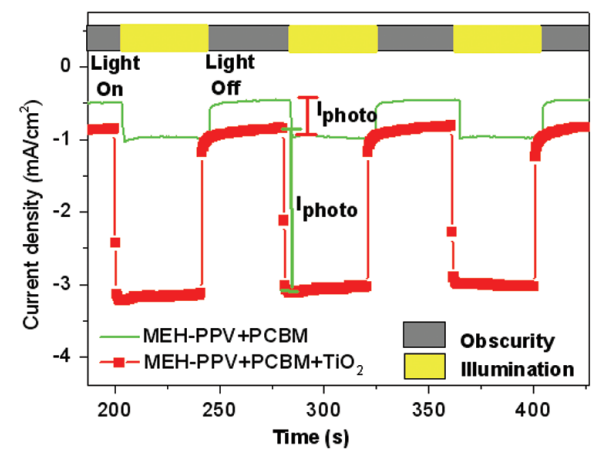

Fig. 6 Photocurrent density-time dependencies obtained with (MEH-PPV/PCBM)/ITO and (MEH-PPV/PCBM+TiO 2 )/ITO electrode in $\mathrm{CH}_{3} \mathrm{CN} / \mathrm{LiClO}_{4}(0.1 \mathrm{~mol} / \mathrm{L})$ at a negative potential of $-0.6 \mathrm{~V}$ observed under illumination and obscurity

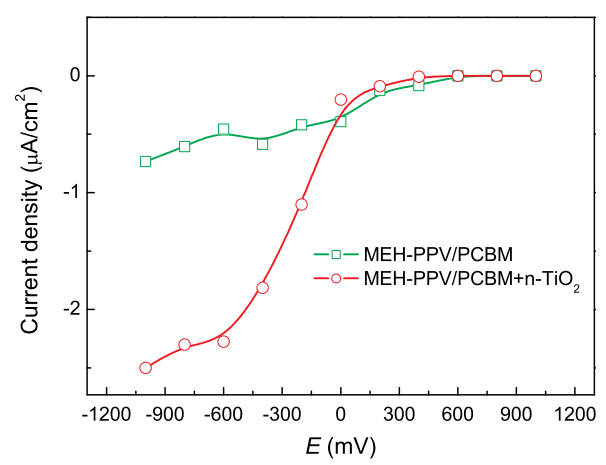

Fig. 7 Photocurrent density as function of applied potential of MEH-PPV/PCBM /ITO electrode doped or undoped with $\mathrm{TiO}_{2}$ nanoparticles in $\mathrm{CH}_{3} \mathrm{CN} / \mathrm{LiClO}_{4}$ solution at light intensity of $100 \mathrm{~mW} / \mathrm{cm}^{2}$

\section{Conclusions}

MEH-PPV, PCBM and inorganic semiconductor nanoparticles $\left(\mathrm{n}-\mathrm{TiO}_{2}\right)$ were dissolved, mixed and spin-coated on indium tin-oxide (ITO) substrate. The incorporation of the $\mathrm{n}-\mathrm{TiO}_{2}$ nanoparticles changes the morphology and increases the roughness of polymers film (MEH-PPV/PCBM). Characterization by cyclic voltammetry showed the electrochemical stability of the composites material, and the photocurrent density characteristic of the composite (MEH$\mathrm{PPV} / \mathrm{PCBM}+\mathrm{n}-\mathrm{TiO}_{2}$ ) was higher than that of the single MEH-PPV/PCBM film.

The study showed that the presence of $n-\mathrm{TiO}_{2}$ particles in the polymeric film improves the photoelectrochemical properties of MEH-PPV/PCBM and gives information on the possibility of application in organic-inorganic photovoltaic cells.

\section{Acknowledgements}

Authors are grateful to Romain Mallet and Guillaume Mabilleau from SCIAM (Angers - France)-Microscopy Service for AFM micrographs.

\section{REFERENCES}

[1] W. Rieh, S. Karg, V. Dyakonov, M. Meier and M.
Schwoerer, J. Lumines. 60-61 (1994) 906.

[2] N.S. Sariciftci, L. Smilowitz, A.J. Heeger and F.P. Wedl, Science 258 (1992) 1474

[3] S. Alem, R.d. Bettignies, J.M. Nunzi and M. Cariou, Appl. Phys. Lett. 84 (2004) 2178.

[4] X. Yang, J. Loos, S.C. Veenstra, W.J.N. Verhees, M. M.Wienk, J.M.Kroon, M.A.J. Michels and R.A.J. Janssen, Nano Lett. 5 (2005) 579.

[5] D.C. Olson, J. Piris, R.T. Collins, S.E. Shaheen and D.S. Ginley, Thin Solid Films 496 (2006) 26.

[6] F.C. Krebs, J.E. Carle, N. Cruys-Bagger, M. Andersen, M.R. Lilliedal, M.A. Hammond and S. Hvidt, Sol. Energy Mater. Sol. Cells 86 (2005) 499.

[7] J.A. Hauch, P. Schilinsky, S.A. Choulis, R. Childers, M. Biele and C.J. Brabec, Sol. Energy Mater. Sol. Cells 92 (2008) 727.

[8] F.C. Krebs, Sol. Energy Mater. Sol. Cells 92 (2008) 715.

[9] A.G. Manoj, A.A. Alagiris wamy and K.S. Narayan, J. Appl. Phys. 94 (2003) 4088.

[10] J. Yang, I. Shalish and Y. Shapira, Phys. Rev. B 64 (2001) 035325.

[11] M. M. Alam and S. A. Jenekhe, Chem. Mater. 16 (2004) 4647.

[12] S.M. Sze, Physics of Semiconductor Device, Wiley, NewYork, 1981, p. 732.

[13] C.W. Tang, Appl. Phys. Lett. 48 (1985) 183.

[14] G. Yu, J. Gao, J. C. Hummelen, F. Wudl and A.J. Heeger, Science 270 (1995) 1789.

[15] D. Gupta, D. Kabra, N. Kolishetti, S. Ramakrishnan and K.S. Narayan, Adv. Funct. Mater. 17 (2007) 226.

[16] H. Hoppe and N.S. Sariciftci, J. Mater. Res. 19 (2004) 1924.

[17] B.P. Rand, J. Xue, S. Uchida and S.R. Forrest, J. Appl. Phys. 98 (2005) 124902.

[18] P.A. van Hal, M.M. Wienk, J.M. Kroon, W.J.H. Verhees, L.H. Sloof, W.J.H. van Gennip, P. Jonkheijm and R.A.J. Janssen, Adv. Mater. 15 (2003) 118.

[19] M. Lira-Cantu and F.C. Krebs, Sol. Energy Mater. Sol. Cells 90 (2006) 2076.

[20] W.J.E. Beek, M.M. Wienk and R.A.J. Janssen, Adv. Mater. 16 (2004) 1009.

[21] K.M. Coakley and M.D. McGehee, Chem. Mater. 16 (2004) 4533.

[22] P. Singh, O.P. Sinha, R. Srivastava, A.K. Srivastava, J. Kaur Bindra, R.P. Singh and M.N. Kamalasanan, Mater. Chem. Phys. 133 (2012) 317.

[23] D. Verma, A. RangaRao and V. Dutta, Sol. Energy Mater. Sol. Cells 93 (2009) 1482.

[24] S.S. Kim, J. Jo, C. Chun, J.C. Hong and D. Kim Yu, J. Photochem. Photobiol. A: Chem. 188 (2007) 364.

[25] F. Habelhames, M. Girtan, A. Manole, L. Lamiri, W. Zerguine and B. Nessark, Nanotech 2012, vol.3, Taylor \& Francis, USA, 2012, pp.420-423.

[26] F. Habelhames, B. Nessark, D. Bouhafs, A. Cheriet and H. Derbal, Ionics 16 (2010) 177.

[27] A. Petrella, M. Tamborra, P.D. Cozzoli, M.L. Curri, M. Striccoli, P. Cosma, G.M. Farinola, F. Babudri, F. Naso and A. Agostiano, Thin Solid Films 451-452 (2004) 64.

[28] Y. Jia, P. Xiao, H. He, J. Yao, F. Liu, Z. Wang and Y. Li, Appl. Surf. Sci. 258 (2012) 6627. 